\title{
An inverted $L$ antenna with a parasitic structure for RFID tag
}

\author{
S. R. Meneses-González and J. López-Bonilla
}

Escuela Superior de Ingeniería Mecánica y Eléctrica, Zacatenco, Instituto Politécnico Nacional, Laboratorio de Compatibilidad Electromagnética, Col. Lindavista CP 07738, México DF

Email: rmenesesg@ipn.mx

Keywords: Inverted L Antenna, Resonance Frequency, RFID Tag, Impedance Antenna, S11 Parameter

ABSTRACT. An inverted L antenna altered by a parasitic resonant structure is designed for RFID tag. In order to determine the performance of varying design parameters on impedance and resonance frequency, HFSS simulation software and experimental tests are carried out. This way, the focus of this work is RFID tag antenna design based on the structure above mentioned.

\section{INTRODUCTION}

Radio Frequency Identification is now generating significant interest in the marketplace because of its robust application capabilities. RFID enables healthcare facilities improve overall safety and operational efficiency because it operates without line-of-sight while providing read/write capabilities for dynamic item tracking, used to identify objects or people with no physical contact or visual supervision, for instance: consumer packaged goods, animal identification, waste management systems, hospitals, libraries, vehicular identification and even humans tagged with RFID chips [1]. RFID applications consist of a wireless communication link between a remote transponder (antenna and integrated circuit), known as the tag, containing the information into the memory block, and an interrogator or reader, which emits radio waves and collects part of them reflected back by the RFID tag.

Various types of antennas for RFID tag have been proposed and the challenge trends to design a RFID tag antenna which dimensions must be enough small size for be assembled with the chip, at the same time satisfy gain, resonance frequency, impedance requirements, in order to match to the passive RFID integrated circuit (IC) and achieve maximum efficiency, as well as bandwidth requirements (low KHz) and low cost [2]. The chips are made to cover three UHF RFID frequency ranges for different regions: Europe (866.5 MHz), North America (915 MHz), Asia (953 MHz), and there are two kinds of the tags, the active tags which are powered by batteries radiating RF electromagnetic energy permanently, for the reader localization, and passive tags powered by the reader's field, the received electromagnetic signal charges an internal charge storing capacitor in the tag chip, which in turn, acts as a power source and supplies the power to the chip energy answering the reader back [3].

In some applications the RFID tag operates as a fixed receiver, firmly attached to the objects to be identified which are generally permanent in the same position, in this case it is enough to use an antenna with not high gain, low radiofrequency, for instance $13.56 \mathrm{MHz}$, in this case HF tags use inductive coupling in the near-field region as the wavelength is much longer, the distance between the reader and the tag is short, with not obstacles, that is, line of sight, and the readout can be taken successfully. But at other RFID applications, for instance vehicular identification, livestock identification, etc., the RFID tag continuously is moving, thus, the antenna polarization is changing constantly, the distance between the reader and the tag is very significant, from what other parameters must be considered, as far field, antenna gain, radiation pattern, operation frequency due to it is shorter wavelength at UHF band [4].

This way, the focus of this work is the tag antenna design for RFID UHF Band, $915 \mathrm{MHz}$, based on L inverted antenna altered with a parasitic resonant structure which complies with small size, acceptable gain and radiation pattern. 


\section{RFID TAG ANTENNA DESIGN}

\subsection{Design Foundations}

The antenna in question consists of a monopole antenna folded in a specific point in order to create two sections, similar to inverted L letter, the horizontal section serves as load to the vertical section, forcing a trapezoidal distribution current along the cooper strip improving the antenna radiation characteristics [5]. The inverted L antenna geometry is shown in Figure 1.

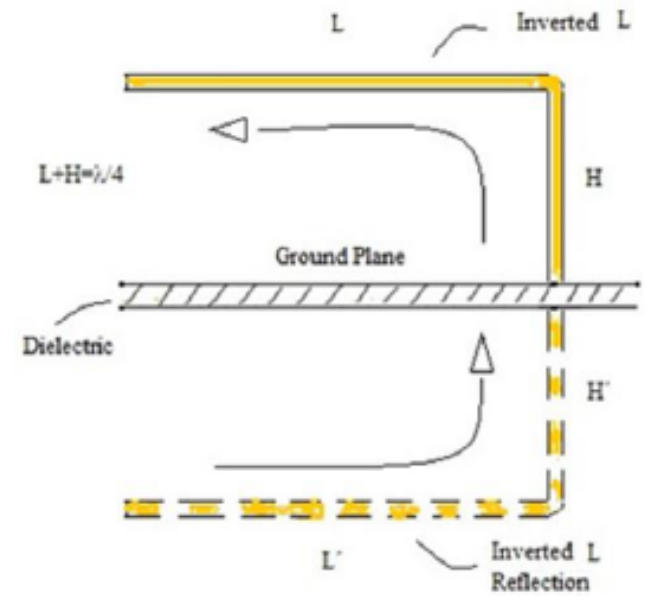

Figure 1. Inverted L antenna geometry.

Evidently the single antenna as shown in Figure 1 is a limited antenna, but in order to take control on resonance frequency adjustment, and improve gain and radiation characteristic, it is possible when it is inserted a parasitic element, a micro strip rectangular ring, between the horizontal section and ground plane, one half of it on front side of the dielectric, that is, PCB (FR4) and the other half on the back side, making a gap between them, with no contact with the inverted $\mathrm{L}$ antenna as shown in Figure 2. This way, the rectangle ring is compressed making up a LC resonant circuit composited by conductor ring inductance and a capacitance due to the gap between the two semi rectangular rings, creating an induced current which flows due to magnetic field vertical to plane $[6,7]$.
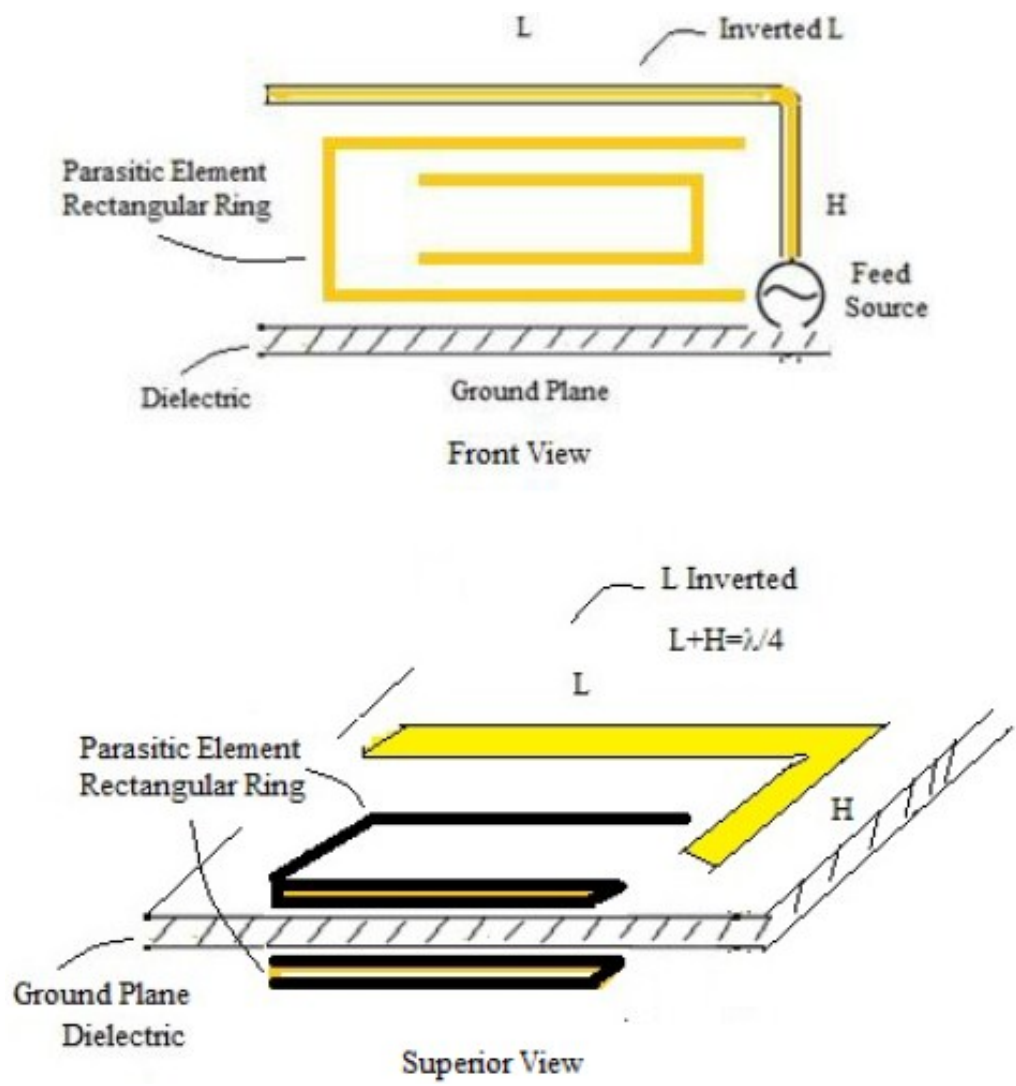

Figure 2. Inverted L antenna with parasitic resonant structure. a). Front view. b). Superior view. 
The equivalent circuit of this kind of antenna is shown in Figure 3, it is composed by resistance, inductance and capacitance of the inverted L element, in the same way, resistance, inductance and capacitance of resonant rectangles, as well as, capacitance between rectangles, and mutual inductance and mutual capacitance between the inverted L element and the parasitic element resonant structure. Mutual coupling has been proven to be a useful mechanism to improve the bandwidth to achieve the frequency bands for mobile antennas when and extra antenna element is coupled to the driven element [8].

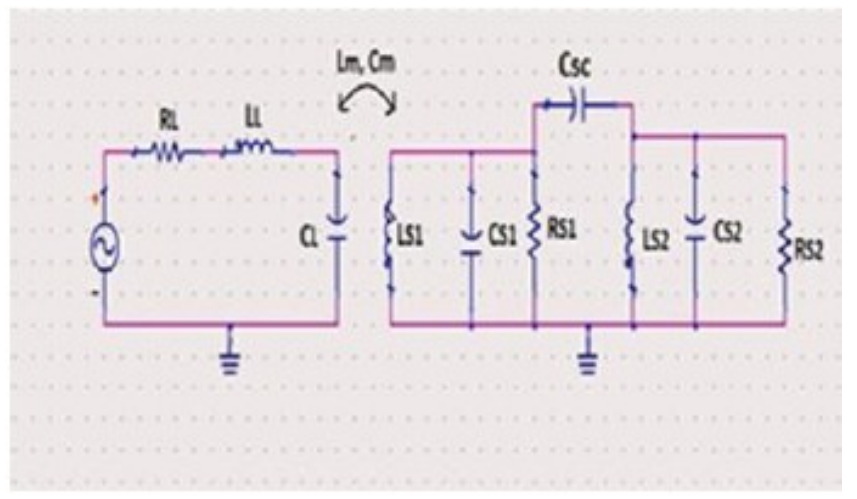

Figure 3. Equivalent circuit.

The resonance frequency is divided into the high-frequency side and low frequency side by adding the ring structure. The L antenna and the rectangular ring on the front side define the low frequency and the back side the high frequency. Each frequency can be adjusted changing the length of the rings. This way, the resonance frequencies are given by [9]:

$$
\begin{aligned}
& f_{1}=\frac{1}{2 \pi \sqrt{\left(L_{s} \pm L_{m}\right)\left(C_{s}+C_{m}\right)}} \\
& f_{2}=\frac{1}{2 \pi \sqrt{\left(L_{s}-L_{m}\right)\left(C_{s}-C_{m}\right)}}
\end{aligned}
$$

For our objective it is necessary just one resonance frequency, $915 \mathrm{MHz}$, the other resonance frequency can be adjusted to European RFID Technology $866.5 \mathrm{MHz}$, and/or Asian RFID Technology, $953 \mathrm{MHz}$.

\subsection{Simulation}

Software HFSS [10] has been used to simulate the designed antenna. The structure and dimensions of designed antenna are shown in Figure 4. Although the inverted L element length should be designed equal to $\lambda / 4$ [11], in order to achieve a resonant frequency equal to $915 \mathrm{MHz}$, it was necessary add a corrective circuit, shown in Figure 5. 


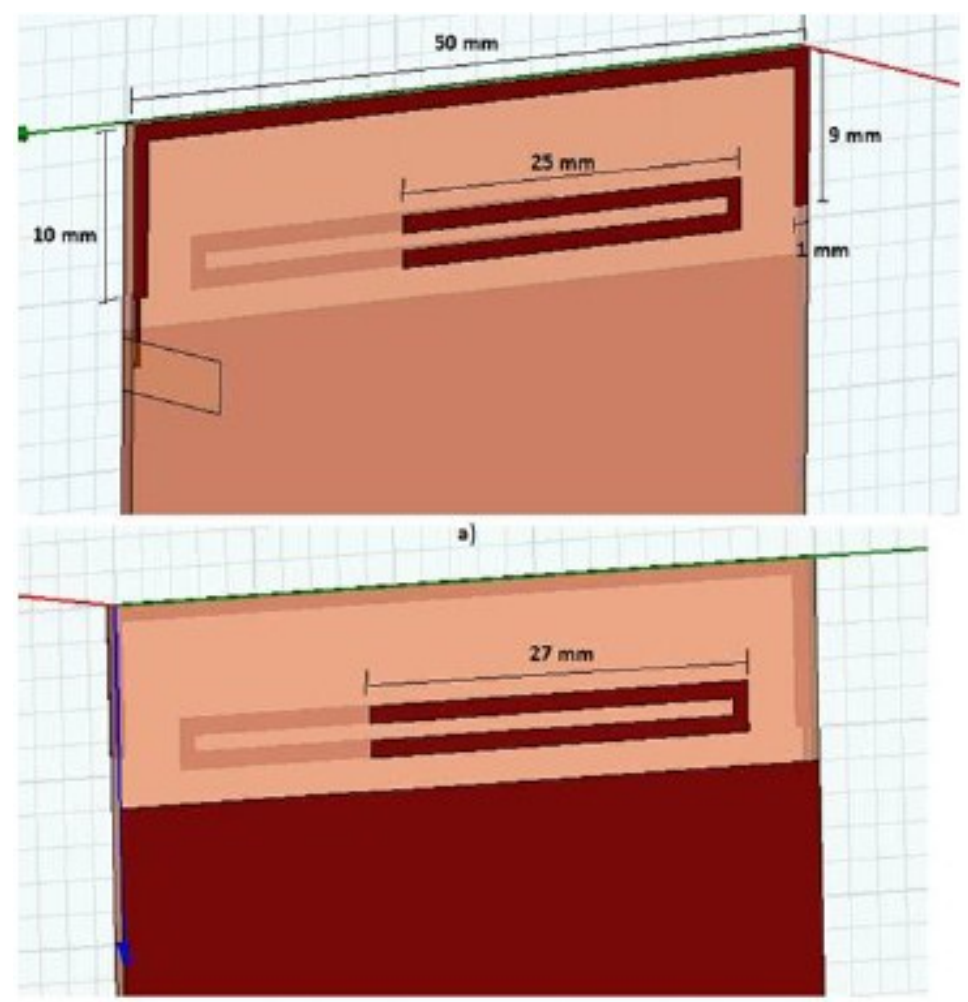

Figure 4. Inverted L antenna with rectangle rings structure (Simulation). a). Front Face. b). Back Face.

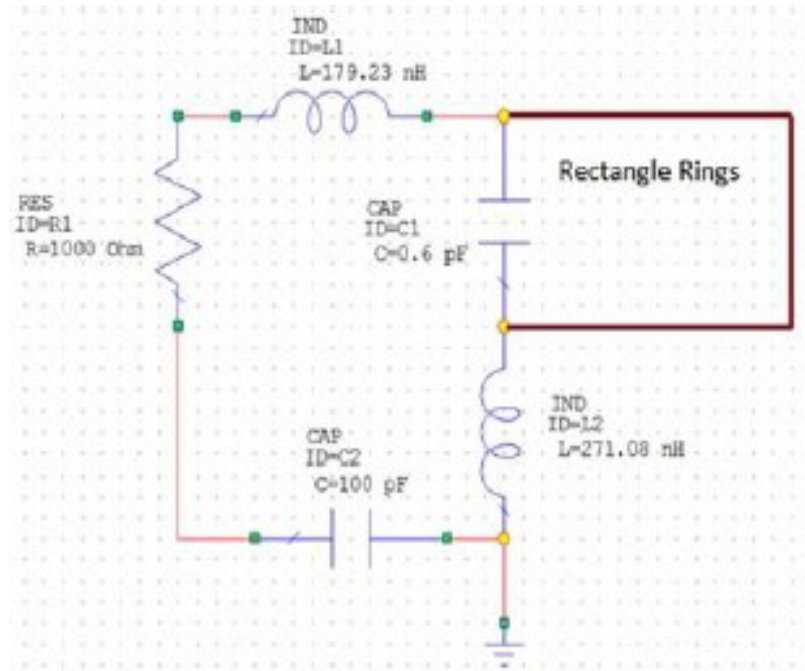

Figure 5. Corrective Circuit.

As a result of simulation, $S_{11}$ parameter graphic is shown in Figure 6 which resonance frequency is $914 \mathrm{MHz}$. In the same way the Radiation Pattern graphic is shown in Figure 7, Plane E is illustrated in red color, and Plane $\mathrm{H}$ is in blue color, as well as, the antenna gain value in a specific direction is shown. 


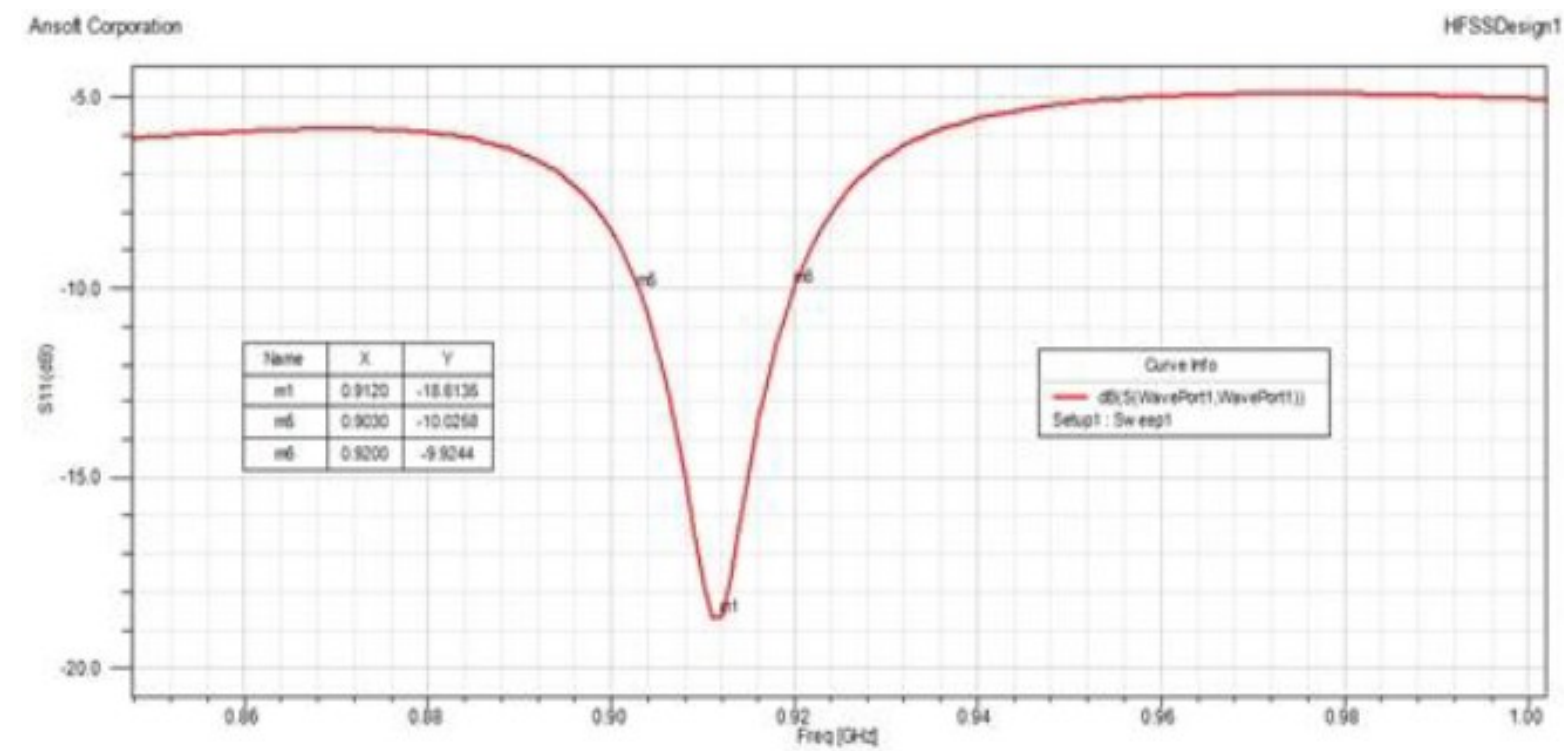

Figure 6. S11 Parameter Graphic (Simulation).
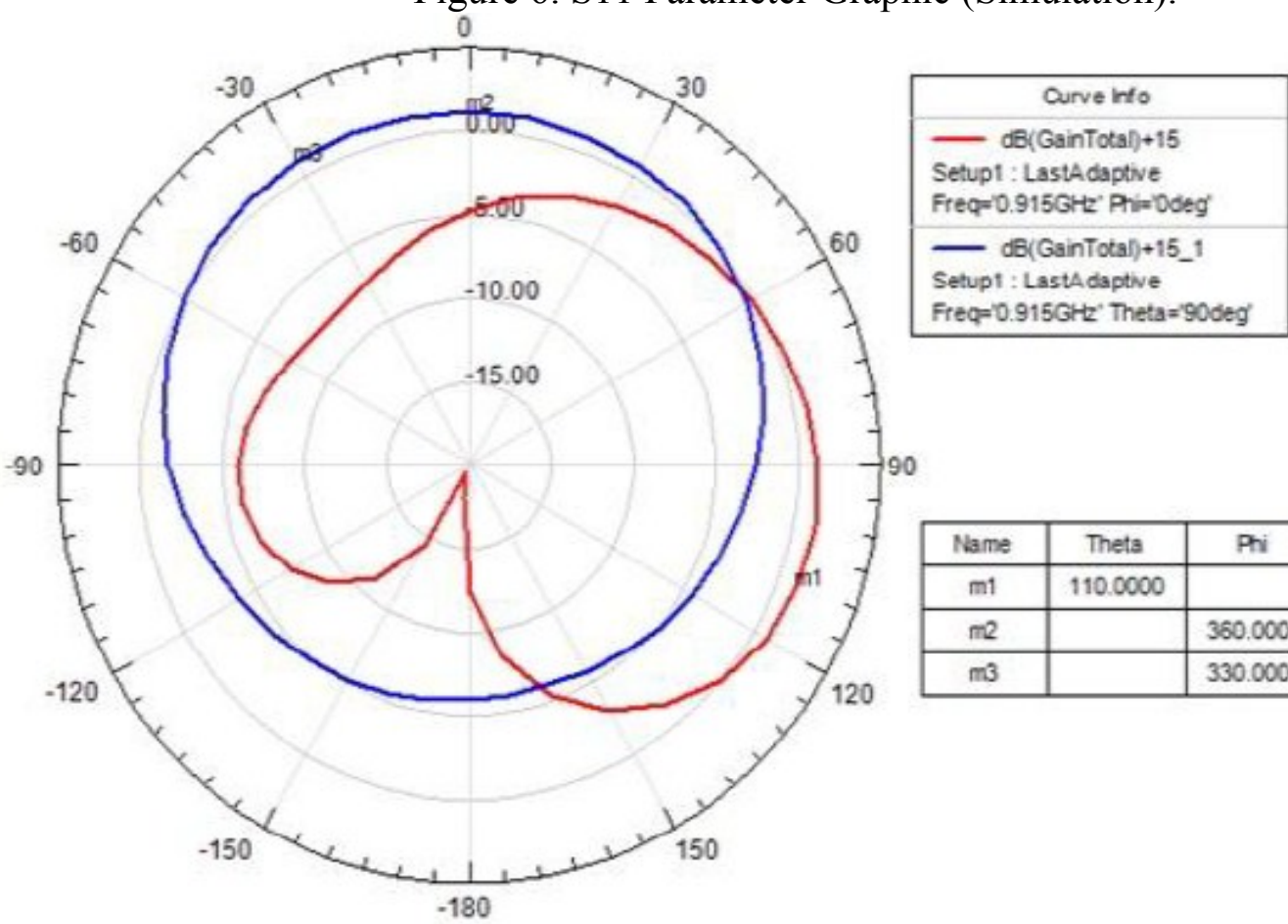

90
\begin{tabular}{|c|c|c|c|c|}
\hline Name & Theta & Phi & Ang & Mag \\
\hline $\mathrm{m} 1$ & 110.0000 & & 110.0000 & 1.2228 \\
\hline $\mathrm{m} 2$ & & 360.0000 & -0.0000 & 1.1614 \\
\hline $\mathrm{m} 3$ & & 330.0000 & -30.0000 & 1.0071 \\
\hline
\end{tabular}

Figure 7. Radiation Pattern (Simulation). Plane E (red color), Plane H (blue color).

\section{IMPLEMENTATION AND MEASUREMENT}

Fig. 8 shows the prototype antenna, the $\mathrm{L}$ inverted monopole antenna and the rings are formed on the front and back side of an FR-4 dielectric substrate $\left(\varepsilon_{r}=4.4, \tan \delta=0.02\right.$, the SMA connector and L antenna are mounted on the front side of the FR4 dielectric substrate [12]. The other components are mounted on the back side of it. The dimensions and values of each one of the components are approximately equal to calculated values. The PCB ground area can be reduced in accordance with experimental results. 


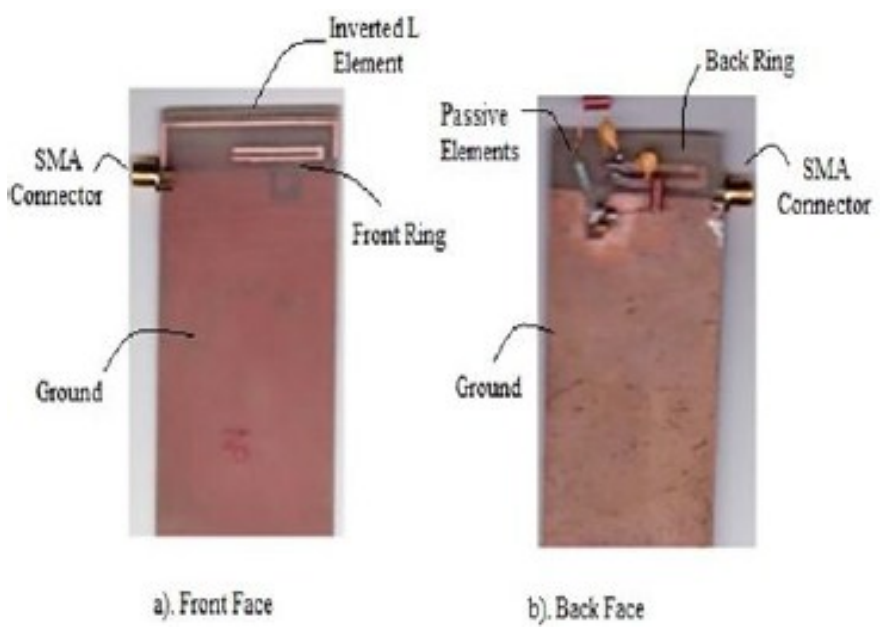

Figure 8. Prototype Antenna.

In order to measure the resonance frequency and impedance of the designed antenna, we have used a Vector Network Analyzer ZVB40 calibrated in the band $500 \mathrm{MHz}-2 \mathrm{GHz}$, as shown in Figure 9. It is possible to observe at Magnitude vs. Frequency graphic, that the resonance frequency is equal to $914.43 \mathrm{MHz},-14.16 \mathrm{~dB}$, in accordance with simulation result.

Measured impedance value of the implemented antenna is shown in the Smith Chart in Fig. 10, equal to $69.11-14.404 \Omega, 12.08 \mathrm{pFd}$, an excellent value in the real part, however, the imaginary part is capacitive, the desired value is an inductive reactance in order to cancel the capacitive part of the chip impedance [13], $Z_{\text {Chip }}=73-j 113 \Omega$, and have the maximum matching. This way in accordance with experimental results, we should trade with maximum efficiency and/or resonance frequency.

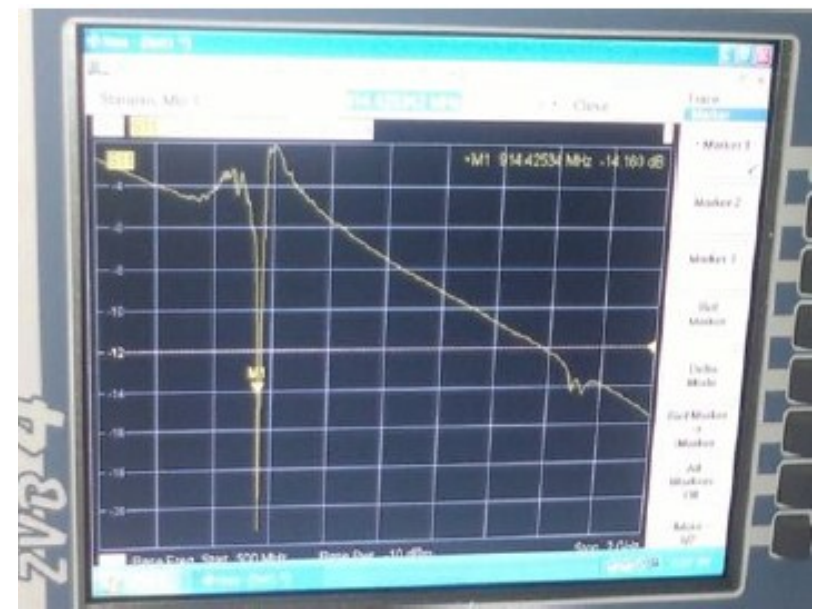

Figure 9. Magnitude vs. Frequency $\left(\mathrm{S}_{11}\right.$ Parameter $)$.

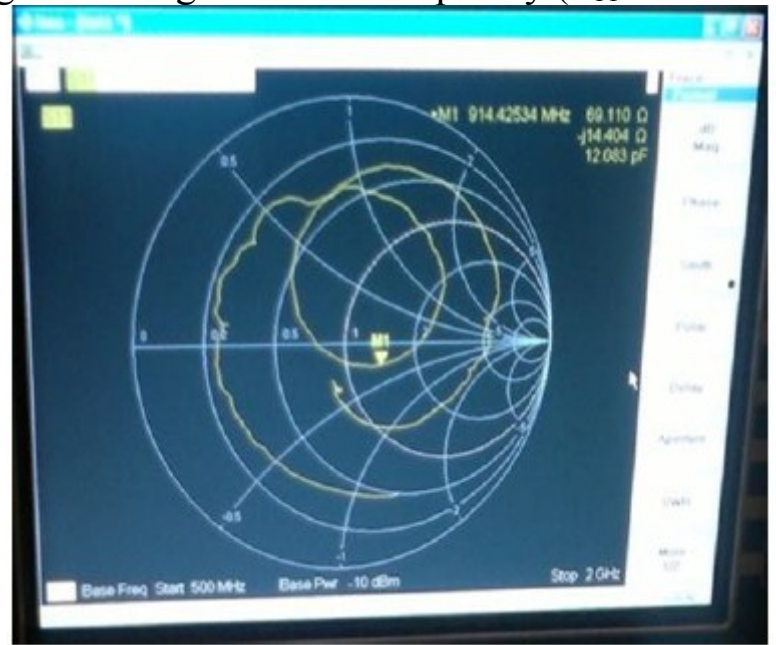

Figure 10. Impedance Antenna. 
On the other hand, in order to measure the radiation pattern of the antenna under test, this one was positioned into an anechoic chamber as shown in Fig. 11 to result in Plane-E and Plane-H radiation pattern shown in Fig. 12. It is possible to observe that these ones are similar with simulation results, there are nulls in specific points, however, even so due to the geometry of the achieved radiation pattern, the RFID tag can be detected by the RFID reader from any position and the feasibility of the designed antenna for this application is guaranteed.

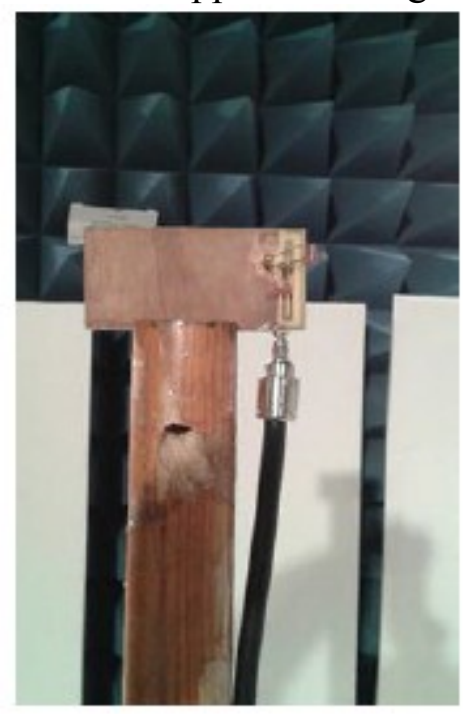

Figure 11. Designed antenna into anechoic chamber.
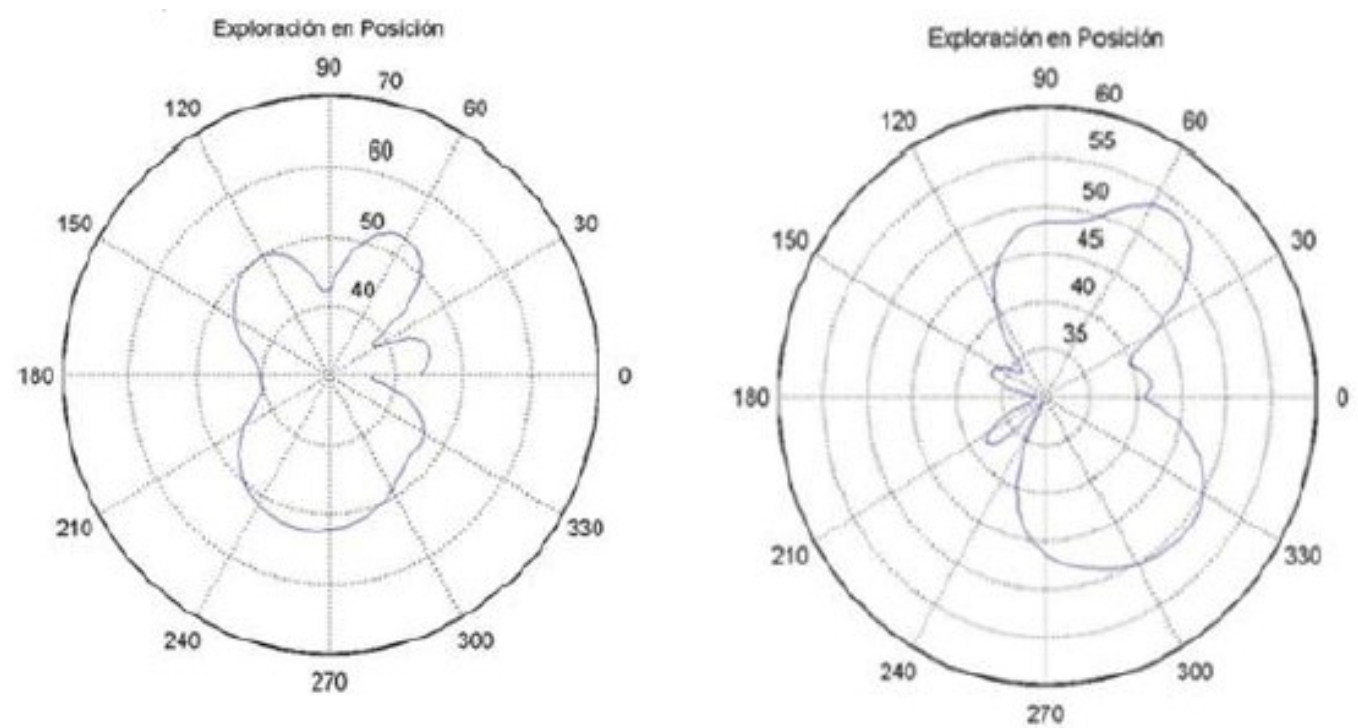

Figure 12. Radiation Pattern, Plane E and Plane H, respectively (Measurement).

\section{CONCLUSIONS}

Antenna design based on driven element coupled to an extra antenna element for RFID tag has been implemented and measured, the mutual coupling has improved the radiation characteristics in order to meet the resonance frequency, radiation pattern and input impedance requirements, as well as, an acceptable antenna gain and small size, this way, the designed antenna is feasible to be applied for RFID Technology. 


\section{REFERENCES}

[1] K. Finkenzeller, "RFID Handbook: Radio-Frequency Identification Fundamentals and Applications", 2nd edition, 2003, John Wiley \& Sons, New York.

[2] K. V. S. Rao, P. V. Nikitin, and S. F. Lam, "Antenna Design for UHF RFID Tags: A Review and a Practical Application", IEEE Transactions on Antennas and Propagation, vol. 53, no. 12, 2005, pp. 3870-3876.

[3] P. V. Nikitin, K. V. S. Rao and S. Lazar, “An overview of near field UHF RFID”, IEEE RFID Conference, 2007, pp.167-174.

[4] L. M. Ng., K. S. Leong, D. M. Hall, \& P. H. Cole, "A small passive UHF RFID tag for livestock identification", IEEE International Symposium on Microwave, Antenna, Propagation and EMC Technologies for Wireless Communications, vol. 1, 2005, pp. 67-70.

[5] N. Takemura, "Inverted-FL antenna with self-complementary structure," IEEE Trans. Antennas Propag., vol. 57, no. 10, pp. 3029-3034, Oct. 2009.

[6] S.-I. Sekine, H. Shoki, and H. Morishita, "Antennas for wireless terminal," IEICE Trans. Commun., vol. E86-B, no. 3, Mar. 2003.

[7] K.-J.Kim,S.Lee,B.-.Kim,J.H.Jung,and Y.J.Yoon,"Small antenna with a coupling feed and parasitic elements for multiband mobile applications," IEEE Antennas Wireless Propag. Lett., vol. 10, pp.290-293, 2011.

[8] E. C. Jordan and K. G. Balmain, "Electromagnetic Waves and Radiating Systems", 1968, Prentice Hall.

[9] R. Collin, “Antennas and Radio Wave Propagation", 1985, Mc Graw Hill.

[10] Ansoft Corporation HFSS [Online]. Available http:// www.ansoft.com/products/hf/hfss/

[11] J. H. Jung, H. Choo, and I. Park, "Design and performance of small electromagnetically coupled monopole antenna for broadband operation," IET Microw. Antennas Propag, vol. 1, no. 2, pp. 536-541, Apr., 2007.

[12] B. D. Braaten, G. J. Owen, D. Vaselaar, R. M. Nelson, C. Bauer-Reich, J. Glower, B. Morlock, M. Reich and A. Reinholz, "A Printed rampart line antenna with a dielectric superstrate for UHF RFID applications”, IEEE Int. Conf. on RFID, 2008, Las Vegas, NV.

[13] N. Popovic, "UHF RFID Antenna: Printed Dipole Antenna with a CPS Matching Circuit and Inductively Coupled Feed", International Journal of Radio Frequency Identification and Wireless Sensor Networks, vol. 1, No. 1, 2011, pp. 28-33. 